\title{
Recurrent insulinoma in a 10-year-old boy with Down's syndrome
}

\author{
Noman Ahmad, Abdulmonem Mohammed Almutawa, Mohamed Ziyad Abubacker, \\ Hossam Ahmed Elzeftawy and Osama Abdullah Bawazir
}

King Faisal Specialist Hospital and Research Centre, Pediatrics, Jeddah, SA, Saudi Arabia
Correspondence

should be addressed

to $\mathrm{N}$ Ahmad

Email

anoman@kfshrc.edu.sa

\section{Summary}

An insulinoma is a rare tumour with an incidence of four cases per million per year in adults. The incidence in children is not established. There is limited literature available in children with insulinoma, and only one case is reported in association with Down's syndrome in adults. Insulinoma diagnosis is frequently missed in adults as well as in children. The Whipple triad is the most striking feature although it has limited application in young children. Hypoglycaemia with elevated insulin, C-peptide and absent ketones is highly suggestive of hyperinsulinism. We present a case of 10-year-old boy with Down's syndrome with recurrent insulinoma. He was initially misdiagnosed as having an adrenal insufficiency and developed cushingoid features and obesity secondary to hydrocortisone treatment and excessive sugar intake. The tumour was successfully localised in the head of the pancreas with an MRI and octreotide scan on first presentation. Medical treatment with diazoxide and octreotide could not achieve normal blood glucose levels. The insulinoma was laparoscopically enucleated and pathological examination confirmed a neuroendocrine tumour. Subsequently, he had complete resolution of symptoms. He had a recurrence after 2 years with frequent episodes of hypoglycaemia. The biochemical workup was suggestive of hyperinsulinism. MRI and PET scan confirmed the recurrence at the same site (head of the pancreas). He had an open laparotomy for insulinoma resection. The pathology was consistent with benign insulinoma, and subsequently, he had complete resolution of symptoms.

\section{Learning points:}

- Insulinoma is a very rare tumour in children; it should be considered in the differential diagnosis of hypoglycaemia with absent ketones.

- Refractory neurological symptoms like seizure, migraine, mood changes and regression of learning abilities should suggest evaluation for hypoglycaemia.

- MRI with contrast and PET scan would localise the majority of pancreatic beta islet cell lesions.

- Medical treatment with diazoxide, octreotide and the addition of corn starch in feeds is not curative but can be supportive to maintain normoglycemia until the surgical resection.

- Surgical resection is the only curative treatment. The surgical procedure of choice (laparoscopic/open laparotomy) depends on local expertise, preoperative localisation, tumour size and number.

- Surgical treatment results in complete resolution of symptoms, but all cases should be closely followed up to monitor for recurrence. The recurrence rate is four times higher in MEN1 cases.

\section{Background}

Hypoglycaemia in infancy and childhood can present secondary to multiple aetiologies, and if it is left untreated or inappropriately treated, it can cause long- term consequences. The most common presentation in this age is ketotic hypoglycaemia due to an acute illness associated with inadequate calorie intake. Children

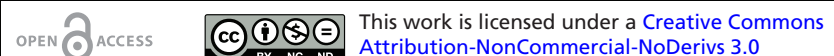
Unported License.
} $\begin{array}{rr}\text { C } 2017 \text { The authors } & \text { http://www.edmcasereports.com } \\ \text { Published by Bioscientifica Ltd }\end{array}$ 
presenting with non-ketotic hypoglycaemia should be evaluated for hyperinsulinism, pituitary hormone deficiencies and fatty acid oxidation defects (1). Dysregulated insulin release prevents glycogenolysis, gluconeogenesis, lipolysis and ketogenesis; this leads to neuroglycopenia with an absence of alternative source of energy (ketone bodies) exposing the developing brain to hypoglycaemic injury (2).

Congenital hyperinsulinism is the most common cause of hyperinsulinaemic hypoglycaemia in infancy. Hypoglycaemia beyond the age of infancy can be due to an insulinoma or beta islet cell tumour of pancreas. Insulinoma is a very rare tumour, and its incidence in children is not estimated. There are only a few case reports in children, and only two case series of eight and nine patients $(2,3)$ are published in the literature (up to 2016). The incidence in adults is four cases per million per year with a median age of presentation in the late fifth and early sixth decade with a slight female predominance. The majority of insulinomas are benign while 5-10\% are malignant and $6 \%$ have an association with multiple endocrine neoplasia type $1(4,5)$.

Hyperinsulinism should be suspected in the presence of Whipple's triad; symptoms/signs of hypoglycaemia, low blood glucose level and resolution of sign and symptoms once blood glucose is raised. The Whipple's triad is not easy to apply in young children as they do not appreciate and express the symptoms of hypoglycemia like adults. A diagnosis of insulinoma is usually delayed in adults and in children due to the vague symptoms. The median interval between the onset of symptoms and diagnosis of an insulinoma is less than 18 months in adults. Common misdiagnoses are seizure disorders, psychiatric disorders and some may present with weight gain $(4,5)$.

An insulinoma diagnosis can be established by a 72-hour fast study; once the patient is symptomatic or develops hypoglycaemia, the critical blood sample is drawn. Dysregulated insulin release is confirmed by inappropriately high levels of insulin in the presence of non-ketotic hypoglycaemia. Exogenous insulin administration can be excluded by elevated C-peptide along with insulin (6).

Once the insulinoma diagnosis is confirmed by a laboratory workup, it is challenging to localise the lesion preoperatively. There are invasive, non-invasive and nuclear imaging options, which can localise the lesion prior to surgery. Medical management to control the symptoms or to shrink the tumour has not shown promising results. The only curative treatment in adult and children is surgical resection of the tumour. The first case of a successful insulinoma resection was reported in 1929 (7).

We present a case of recurrent insulinoma in a ten-year-old boy with Down's syndrome. He was misdiagnosed with adrenal insufficiency and treated with hydrocortisone for one year before the diagnosis of insulinoma was confirmed. He re-presented nearly two years after resection with recurrence. He did not have an MEN1 gene mutation.

\section{Case report}

A ten-year-old boy was presented with a history of decreased activity, excessive sleep, increased appetite, rapid weight gain and frequent episodes of tonic clonic seizures. He was evaluated at a local hospital one year ago and diagnosed with hypoglycaemia secondary to adrenal insufficiency and commenced on hydrocortisone treatment. Symptoms of hypoglycaemia remained refractory to hydrocortisone, and the dose was increased up to $10 \mathrm{mg}$ twice daily. He had a history of a surgical repair of a ventricular septal defect. At presentation, he had obvious clinical features of trisomy 21 and cushingoid appearance. His weight was $55 \mathrm{~kg}$ (97th centile; $2.21 \mathrm{SDS}$ ), his height was $131 \mathrm{~cm}$ (5th centile; -1.2 SDS) and body mass index was $32.2 \mathrm{~kg} / \mathrm{m}^{2}$ (99th centile; $2.5 \mathrm{SDS}$ ).

Table 1 Critical blood samples result (at the onset of hypoglycaemia).

\begin{tabular}{lcc} 
& First presentation \\
\hline Blood glucose & & $2.6 \mathrm{mmol} / \mathrm{L}$ \\
Insulin & $832 \mathrm{pmol} / \mathrm{L}$ \\
C-peptide & $2.5 \mathrm{nmol} / \mathrm{L}$ \\
Growth hormone & $<0.1 \mathrm{ng} / \mathrm{mL}$ \\
Cortisol & $241 \mathrm{nmol} / \mathrm{L}$ \\
Ammonia & $41 \mu \mathrm{mol} / \mathrm{L}$ \\
Ketones & Negative \\
Acyl Carnitine & Normal \\
Amino acid profile & Normal \\
\hline
\end{tabular}

\begin{tabular}{ccc}
\hline Second presentation & & Normal range \\
\hline $1.6 \mathrm{mmol} / \mathrm{L}$ & & $4.0-7.0$ \\
$325.9 \mathrm{pmol} / \mathrm{L}$ & $17.8-173$ \\
$1.58 \mathrm{nmol} / \mathrm{L}$ & $0.80-0.650$ \\
$4.0 \mathrm{ng} / \mathrm{mL}$ & $0-10$ \\
$294 \mathrm{nmol} / \mathrm{L}$ & $171-536$ \\
$56 \mu \mathrm{mol} / \mathrm{L}$ & $0-55$ \\
Negative & \\
- & \\
- & \\
\hline
\end{tabular}



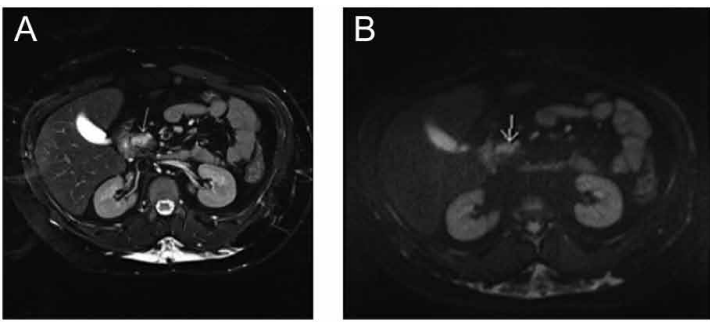

\section{Investigations}

He was admitted to our unit for diagnostic workup. He was put on supervised elective fast although did not require a prolonged fast as he had frequent hypoglycaemic episodes. Critical blood sample (at the onset of hypoglycaemia) results are shown in Table 1 . The hydrocortisone was weaned over few weeks.

Other investigations showed a normal insulin-like growth factor, HbA1c 4.0\%, karyotype $47 \mathrm{XY}+21$ and absence of MEN1 gene mutation. A diagnosis of an insulinoma is confirmed by the presence of elevated insulin and C-peptide associated with non-ketotic hypoglycaemia. The cortisol and growth hormone levels were not elevated probably due to the recurrent hypoglycaemic episodes and thus an insidious onset of hypoglycaemia in contrast to provocation tests.

He underwent a radiological workup to localise the lesion in pancreas. Ultrasound scan of the abdomen did not reveal any masses or lesions. MRI of abdomen with contrast revealed a mass in the pancreatic head measuring $2.3 \times 1.6 \times 1.7 \mathrm{~cm}$. There was high signal intensity in $\mathrm{T} 2$ and low signal intensity in T1 images, diffusion restriction and hypervascularity (Fig 1). Octreotide nuclear scan showed a

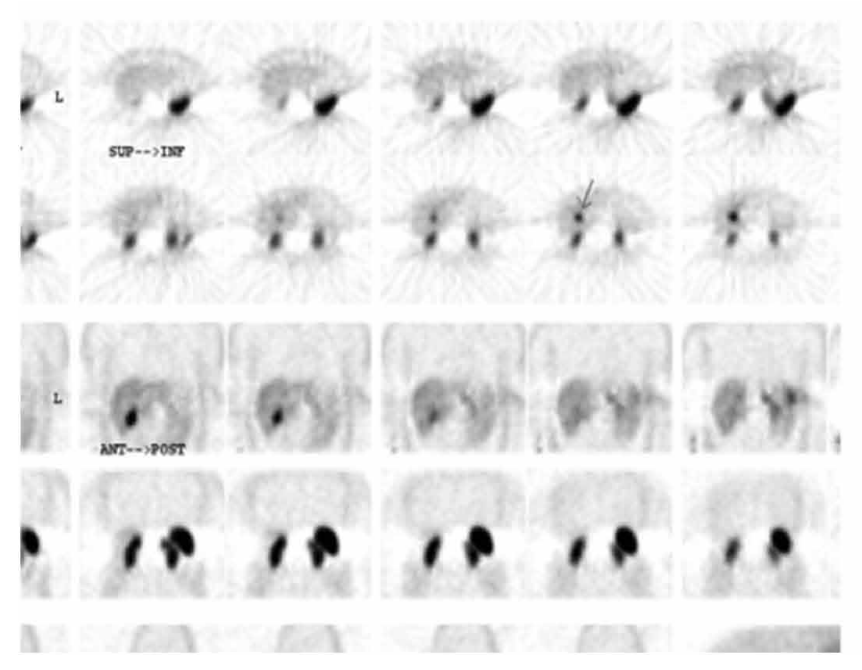

Figure 2

Octreotide scan of high tracer uptake at the head of pancreas.

\section{Figure 1}

(A) High signal intensity on T2 image.

(B) Diffusion restriction on MRI. (C) Hypervascular enhancing lesion. high tracer uptake at pancreatic head consistent with the MRI findings, and no lymph nodes or metastatic lesions were detected (Fig. 2).

\section{Management}

We started high dextrose infusion to maintain the blood glucose, but we were unable to maintain his normal blood glucose with 15\% dextrose infusion. Surgical treatment was delayed due to the difficulty in arranging an MRI under general anaesthesia. A central venous line was placed, and he was given $20 \%$ dextrose along with oral diazoxide up to $100 \mathrm{mg}$ three times a day. He developed fluid retention with pulmonary oedema requiring high oxygen therapy secondary to the diazoxide treatment. Diazoxide was stopped, and he was started on octreotide subcutaneous injections. The blood glucose continued to fluctuate on the high dextrose infusion and octreotide $100 \mu g$ three times a day.

Once the lesion was localised on the MRI and octreotide scan, he underwent laparoscopic enucleation of insulinoma. An insulinoma was identified in the pancreatic head as dark colour lesion different from the rest of pancreatic tissue. The pathologic examination

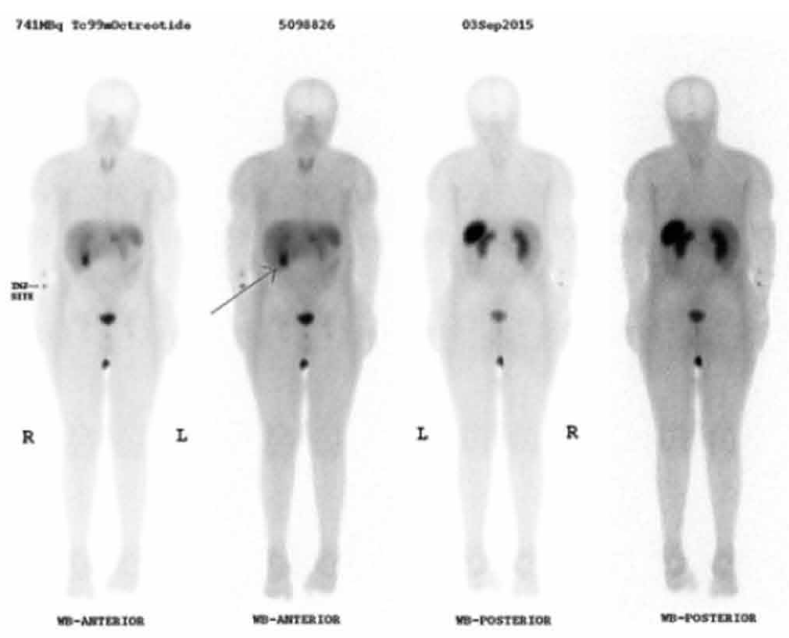




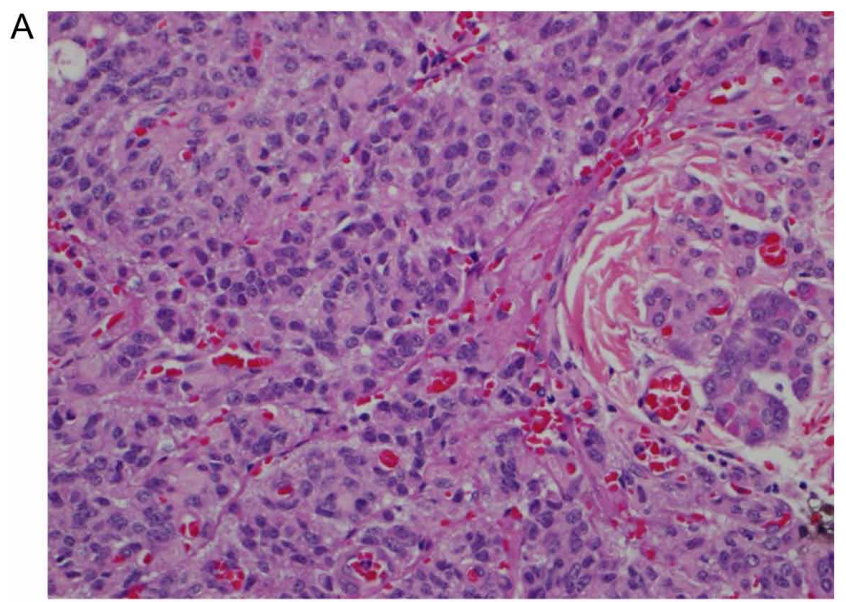

B

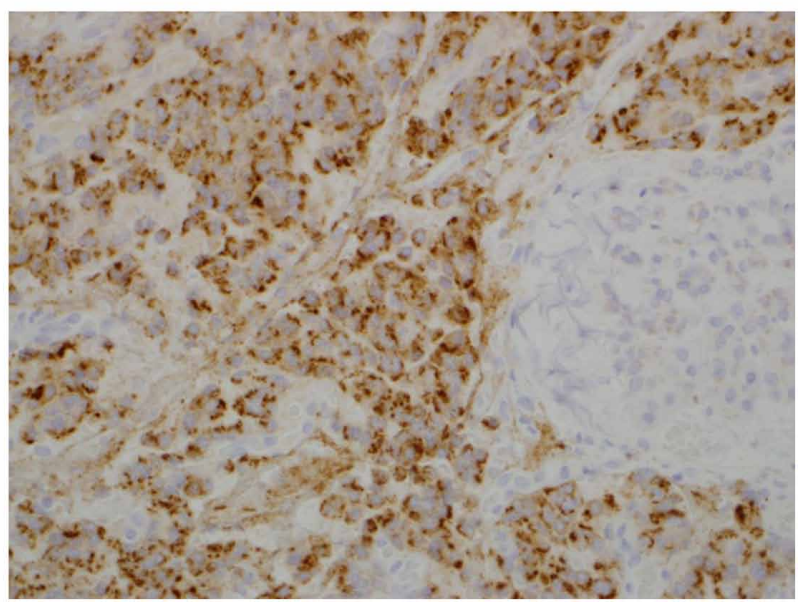

Figure 3

(A) The tumour cells shows nesting, and focally trabecular, growth pattern. The stroma is highly hypervascular, and the tumour cells exhibit fine nuclear chromatin pattern. Small portion of pancreatic exocrine acini is noted on the right side of the field. Original magnification: $400 x$

(B) Strong positivity for chromogranin by immunohistochemistry staining is observed in the tumour cells, but not in the pancreatic exocrine acini on the right side of the field. Original magnification: $400 \times$.

revealed a well-differentiated neuroendocrine tumour grade 1 , with a size of $2 \mathrm{~cm}$, mitotic rate of $<2 / 10 \mathrm{hpf}$ and Ki-67 proliferative index of $<2 \%$ (Fig. 3A). The tumour cells expressed positivity for the following immunohistochemical markers: chromogranin, synaptophysin and Cam 5.2 (Fig. 3B). The blood glucose started rising after surgery, and he came off all the dextrose infusions and octreotide therapy soon after surgery. Subsequently, he was discharged home in stable condition with no extra sugar intake or medication.

\section{Recurrence}

He was followed up regularly in a paediatric endocrinology clinic. After one year, his weight dropped to $44 \mathrm{~kg}, 0.95$ SDS (55 kg on presentation), and he was a happy child with normal blood glucose and no further seizures. Two years after his first surgery, he presented with recurrent episodes of hypoglycaemia. A critical blood sample collected at the onset of hypoglycaemia confirmed the diagnosis of insulinoma (Table 1). MRI with contrast showed tumour recurrence at the same site as the first lesion in the head of pancreas (Fig. 4). He also had ${ }^{18}$ F-FDG PET scan, which revealed high uptake in the area shown on MRI with no other lesion identified (Fig. 5). He underwent a second operation and had a laparotomy for enucleation of a tumour measuring $1.5 \mathrm{~cm}$ in diameter. He recovered well after surgery and achieved normal blood glucose without any treatment.

\section{Discussion}

We present a case of recurrent insulinoma in a young 10-year-old boy with Down's syndrome. Insulinoma incidence is extremely rare in children, and there is no estimated incidence in this age group. Insulinoma is often diagnosed after a long duration of symptoms. In the adult series, up to $20 \%$ are misdiagnosed $(5,8)$. Children are also misdiagnosed as refractory seizures, insomnia and migraine headaches in different case reports $(9,10)$. This case was also initially misdiagnosed as secondary adrenal insufficiency due to the low adrenocorticotropic hormone with hypoglycaemia. Insulinoma recurrence is four times more common at 10 years with MEN1 compared with those who do not have the MEN1 gene mutation (5). This young boy was completely symptom free for nearly two years, but presented with recurrence despite absent MEN1 gene mutation. There is only one case of insulinoma reported in literature associated with Down's syndrome
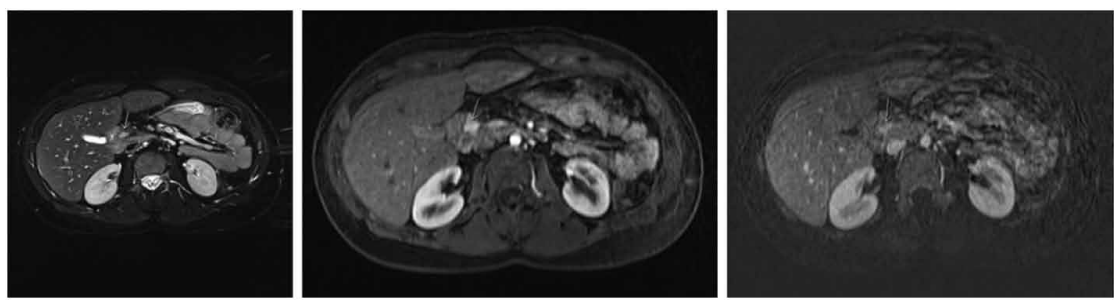

Figure 4

MRI showing the recurrence at pancreatic head. 


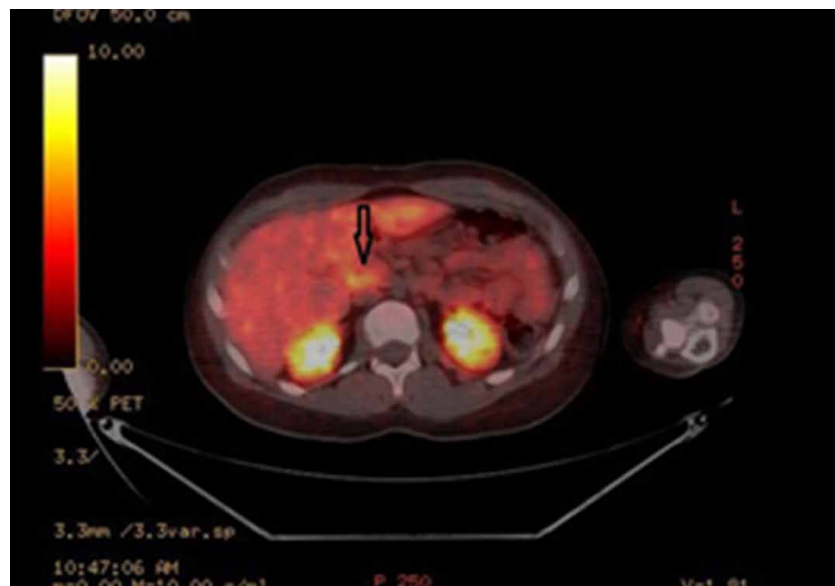

Figure 5

18F-FDG PET scan showing high uptake at the head of pancreas.

at the age of 35 years (11); no cases have been reported in the paediatric population

Down's syndrome has a well-known association with neoplasms. The majority of case reports are haematopoietic malignancies. $\mathrm{H}$ Ehara et al reported retrospective data on 1514 cases of Down's syndrome from an autopsy database; 104 cases had a malignant neoplasm out of which $83.7 \%$ were haematopoietic malignancies and $16.3 \%$ were solid tumours. There were eight cases of benign tumours. Only pancreatic tumour was reported, and this was a pancreatic islet cell adenocarcinoma at the age of 45 years (12).

Hypoglycaemia in infancy can be a presentation of congenital hyperinsulinism, growth hormone deficiency or adrenal insufficiency. Insulinoma should be considered in children presenting with non-ketotic hypoglycaemia beyond the age of infancy as hypopituitarism does not usually present with isolated hypoglycaemia in older children. Growth hormone and cortisol may not increase if hypoglycaemia is insidious or if there are frequent episodes of hypoglycaemia as seen in this case. Inappropriately high insulin and C-peptide in the presence of non-ketotic hypoglycaemia indicate beta islet cell lesion. Other causes of non-ketotic hypoglycaemia are carnitine deficiency or beta oxidation defects like MCAD (medium-chain acylcoenzyme A dehydrogenase deficiency) presenting with high free fatty acid and low insulin levels (10).

Localisation of an insulinoma is challenging and critical due to probability of multiple, diffuse or extra pancreatic lesions. Up to $10 \%$ of insulinomas are malignant and 6\% are associated with MEN1. Different invasive and non-invasive imaging modalities are used to localise the lesion, although the sensitivities and specificities are not documented in children. Invasive modalities include ASVS (arterial stimulation and venous sampling) in which different arteries supplying pancreatic tissue are infused with calcium followed by hepatic venous sampling to detect a rise in insulin; THPVS (trans-hepatic portal venous sampling) and endoscopic ultrasound. W.H. Peranteau et al. reported eight cases of insulinoma in children; one had ASVS and another one had THPVS and both accurately localised the lesion, whereas endoscopic ultrasound localised the lesion in two cases out of five (3). MRI is a non-invasive modality with high sensitivity and specificity in adults. W.H. Peranteau et al. reported 50\% (3/6), while R. Padidela et al. reported $88 \%(7 / 8)$ correct localisation of the lesion with MRI (2). Octreotide scans have poor detection of insulinoma as they usually do not express enough somatostatin receptors (13). 18F-DOPA is taken up by neuroendocrine cells and used to differentiate between focal and diffuse lesions in congenital hyperinsulinism; 18F-DOPA PET scan is inconsistent in localising insulinoma in children: $100 \%(3 / 3)$ in one series and 50\% (2/4) in another $(2,3)$. Glucagon-like peptide 1 (GLP1) receptor imaging is a new and non-invasive modality, which has shown $100 \%$ successful localisation in a small study of six cases (14). Radiolabelled peptides have shown promising results in localising the lesions in oncology and endocrinology cases. GLP1 binds to specific receptors on beta islet cell to induce insulin release. GLP1 receptors are expressed on insulinomas in large quantity (15). In our case, MRI detected the lesion correctly at first presentation as well as at recurrence. An octreotide scan performed at first presentation and PET scan at recurrence and both detected the lesion correctly.

Medical treatment is not usually effective in treating the hypoglycaemia as seen in this case. Diazoxide or octreotide along with dextrose infusion or the addition of corn starch is used to maintain the blood glucose until surgical resection of the tumour can be undertaken although the response is inconsistent $(2,3)$. Diazoxide causes severe fluid retention, congestive heart failure and pulmonary oedema as experienced with this case, which may be managed by loop diuretics otherwise it has to be discontinued. Everolimus is an inhibitor of the mammalian target rapamycin (mTOR), a newer agent with limited experience in malignant cases; it inhibits endothelial growth factor and thus limits the beta cell proliferation, but there are not enough clinical trials of using mTOR in paediatrics.

Surgical treatment is the only curative option for insulinoma. Enucleation of the insulinoma or limited pancreatic resection can be performed laparoscopically or by conventional laparotomy. Successful preoperative 
localisation of the insulinoma can provide an opportunity for laparoscopic resection. Small discrete insulinoma can be successfully resected laparoscopically. Intraoperative identification of lesions by manual palpation and ultrasound supports the choice of open laparotomy. Children with MEN1 have a higher probability of multiple lesions and may benefit with open laparotomy. Some centres strongly recommend laparotomy (3), while others may follow good laparoscopic experience in adults if there is preoperative localisation (16).

Surgical resection provides a complete resolution of hypoglycaemia in the majority of cases, but they still require a close follow-up due to the risk of recurrence. In the adult series, there was $6 \%$ recurrence requiring further surgery. MEN1 is associated with a higher recurrence rate of up to $21 \%$ compared with $5 \%$ without MEN1 after ten years of first presentation (5). Early recurrence in the same site is suggestive of residual tumour growth left behind during the first resection (17). MEN1 is also associated with a higher rate of malignancy, larger tumour size, multiple lesions and lympho-vascular invasion.

\section{Declaration of interest}

The authors declare that there is no conflict of interest that could be perceived as prejudicing the impartiality of the research reported.

\section{Funding}

This research did not receive any specific grant from any funding agency in the public, commercial or not-for-profit sector.

\section{Patient consent}

The consent for publication of this study was obtained from the brother of the child.

\section{Author contribution statement}

Dr Noman Ahmad is the physician responsible for care; he contributed mainly to the writing of the manuscript. Dr Almutawa (histopathologist), Dr Abubacker (radiologist) and Dr Elzeftawy (radiologist in nuclear medicine) contributed to diagnosing the case and reviewing the manuscript.

\section{References}

1 LaFranchi S 1987 Hypoglycemia of infancy and childhood. Pediatric Clinics of North America 34 961-982. (doi:10.1016/S00313955(16)36297-6)
2 Padidela R, Fiest M, Arya V, Smith VV, Ashworth M, Rampling D, Newbould M, Batra G, James J, Wright NB, et al. 2014 Insulinoma in childhood: clinical, radiological, molecular and histological aspects of nine patients. European Journal of Endocrinology 170 741-747. (doi:10.1530/EJE-13-1008)

3 Peranteau WH, Palladino AA, Bhatti TR, Becker SA, States LJ, Stanley CA \& Adzick NS 2013 The surgical management of insulinomas in children. Journal of Pediatric Surgery 48 2517-2524. (doi:10.1016/j.jpedsurg.2013.04.022)

4 Placzkowski KA, Vella A, Thompson GB, Grant CS, Reading CC, Charboneau JW, Andrews JC, Lloyd RV \& Service FJ 2009 Secular trends in the presentation and management of functioning insulinoma at the Mayo Clinic, 1987-2007. Journal of Clinical Endocrinology \& Metabolism 94 1069-1073. (doi:10.1210/jc.2008-2031)

5 Service FJ, McMahon MM, O’Brien PC \& Ballard DJ. Functioning insulinoma-incidence, recurrence, and long-term survival of patients: a 60-year study. In Mayo Clinic Proceedings 1991 Jul 31 (Vol. 66, No. 7, pp. 711-719). Elsevier.

6 Tucker ON, Crotty PL \& Conlon KC 2006 The management of insulinoma. British Journal of Surgery 93 264-275. (doi:10.1002/bjs.5280)

7 Howland G, Campbell WR, Malthby EJ \& Robinson WL 1929 Dysinsulinism: Convulsions and coma due to islet cell tumor of pancreas, with operation and cure. JAMA 93 674. (doi:10.1001/ jama.1929.02710090014006)

8 Harrington MG, McGeorge AP, Ballantyne JP \& Beastall G 1983 A prospective survey for insulinomas in a neurology department. Lancet 321 1094-1095. (doi:10.1016/S0140-6736(83)91923-2)

9 Kao KT, Simm PJ \& Brown J 2014 Childhood insulinoma masquerading as seizure disorder. Journal of Paediatrics and Child Health 50 319-322. (doi:10.1111/jpc.12399)

10 Gozzi Graf T, Brändle M \& Clerici T 2014 Insulinoma: only in adults?case reports and literature review. European Journal of Pediatrics 173 567-574. (doi:10.1007/s00431-013-2005-8)

11 Morgan JR 1989 A case of Down's syndrome, insulinoma and anorexia. Journal of Intellectual Disability Research 33 185-187. (doi:10.1111/j.1365-2788.1989.tb01465.x)

12 Ehara H, Ohno K \& Ito H 2011 Benign and malignant tumors in Down syndrome: analysis of the 1514 autopsied cases in Japan. Pediatrics International 53 72-77. (doi:10.1111/j.1442-200X.2010.03189.x)

13 Mirallié E, Pattou F, Malvaux P, Filoche B, Godchaux JM, Maunoury V, Palazzo L, Lefebvre J, Huglo D \& Paris JC 2011 Value of endoscopic ultrasonography and somatostatin receptor scintigraphy in the preoperative localization of insulinomas and gastrinomas. Gastroentérologie clinique et biologique 25 360-366.

14 Christ E, Wild D, Forrer F, Brandle M, Sahli R, Clerici T, Gloor B, Martius F, Maecke H \& Reubi JC 2009 Glucagon-like peptide-1 receptor imaging for localization of insulinomas. Journal of Clinical Endocrinology \& Metabolism 94 4398-4405. (doi:10.1210/jc.2009-1082)

15 Sowa-Staszczak A, Trofimiuk-Müldner M, Stefańska A, Tomaszuk M, Buziak-Bereza M, Gilis-Januszewska A, Jabrocka-Hybel A, Głowa B, Małecki M \& Bednarczuk T 2016 99m Tc Labeled Glucagon-Like Peptide-1-Analogue (99m Tc-GLP1) Scintigraphy in the Management of Patients with Occult Insulinoma. PLoS One 11 e0160714. (doi:10.1371/journal.pone.0160714)

16 Assalia A \& Gagner M 2004 Laparoscopic pancreatic surgery for islet cell tumors of the pancreas. World Journal of Surgery 28 1239-1247. (doi:10.1007/s00268-004-7617-8)

17 Service FJ 2006 Recurrent hyperinsulinemic hypoglycemia caused by an insulin-secreting insulinoma. Nature Reviews Endocrinology 2 467-470. (doi:10.1038/ncpendmet0263) 